\title{
Light scattering by filled liquid crystals in anomalous-diffraction approach
}

\author{
M.F.Lednei ${ }^{1}$, I.P.Pinkevich ${ }^{1}$, T.J.Sluckin ${ }^{2}$ \\ 1 Kyiv Taras Shevchenko University, Physics Faculty, \\ 6 Glushkov Ave., 03022 Kyiv, Ukraine \\ 2 University of Southampton, Faculty of Mathematical Studies, \\ Southampton, SO17 1BJ, United Kingdom
}

Received August 1, 2000

\begin{abstract}
The differential and total light scattering cross sections by LCs which contain hard macroscopic spherical and cylindrical particles are theoretically studied using the anomalous-diffraction approach. The influence of form and size of particles, the type and strength of director anchoring on the particle surface as well as light wave polarization on the light scattering is analysed.
\end{abstract}

Key words: liquid crystals, light scattering, anomalous-diffraction approach

PACS: $61.30 . \mathrm{Cz}, 42.70 . \mathrm{Df}, 61.30 . \mathrm{Gd}, 61.30 . \mathrm{Hn}, 61.30 . \mathrm{Pq}$

\section{Introduction}

As is known, in the cells of nematic liquid crystals (LCs) filled with small hard particles (briefly, in filled liquid crystals - FLCs) one can observe intensive light scattering on inhomogeneities of director field caused by the particles [1]. The contribution of the particles themselves to the light scattering is small due to their small relative volume and thus can be neglected. If the external permanent electric field is properly switched on the director field, distortions decrease and lead to the decrease of light scattering and thus to the increase of nematic cell transparency. Due to this effect the FLCs are very perspective media for applications in displays and in other optoelectronic devices [2].

In papers $[3,4]$ we considered the light scattering cross sections by FLCs in Rayleigh-Gans approximation which is applicable in the case of director inhomogeneities with characteristic size $R_{\mathrm{ch}}<\lambda$, where $\lambda$ is the wavelength of light. In present paper we consider the light scattering in FLCs in the opposite case $R_{\mathrm{ch}}>\lambda$ which takes place for particles of large size or for strong director anchoring on the particle surface when the disclination arises near the particle. In this case the light scattering can be treated within the anomalous-diffraction approach (ADA) [5]. The 
last was successfully used in paper [6] to analyze the light scattering by LC droplets in polymer matrix.

In section 2 we introduce the general expressions for differential cross sections following the basic results obtained within ADA in paper [6]. Sections 3, 4 treat light scattering from LCs filled with spherical and cylindrical particles, correspondingly. Conclusions are presented in section 5.

\section{General expressions for light scattering cross sections}

The light scattering differential cross section can be written as

$$
\frac{\mathrm{d} \sigma}{\mathrm{d} \Omega}=\frac{1}{k^{2}}\left\{\left|S_{11} \cos \alpha+S_{12} \sin \alpha\right|^{2}+\left|S_{21} \cos \alpha+S_{22} \sin \alpha\right|^{2}\right\}
$$

where $S_{i j}$ are the components of scattering matrix $\hat{S}$ which according to paper [6] assumes in ADA the following form:

$$
\hat{S}=\frac{k^{2}}{2 \pi} \iint_{(A)}\left[\hat{1}-\hat{P}\left(\vec{r}^{\prime \prime}\right)\right] \mathrm{e}^{\mathrm{i} \vec{k}^{\prime} \vec{r}^{\prime \prime}} \mathrm{d} A .
$$

Here $\vec{k}, \vec{k}^{\prime}$ are the wave vectors of the incident and the scattered waves (but $k=k^{\prime}$ ), the integral goes over the area $A$ covered by a projection of the scattering object on the plane which is orthogonal to the wave vector $\vec{k} ; i, j=1,2$ denote the components parallel and orthogonal to the scattering plane (plane of vectors $\vec{k}, \vec{k}^{\prime}$ ), $\alpha$ is the angle between the polarization vector of the incident wave and the scattering plane, $\hat{1}$ is a unit matrix, matrix $\hat{P}\left(\vec{r}^{\prime \prime}\right)$ describes the phase shift and the rotation of the polarization vector for a ray passing the area $A$ at point $\vec{r}^{\prime \prime}$, the concrete view of $\hat{P}\left(\vec{r}^{\prime \prime}\right)$ depends on the character of scattering object (the director field distortion in our case).

\section{LC filled with spherical particles}

Let the LC be filled with hard spherical particles of radius $R$. The concentration of particles is assumed to be small, so the director field distortions caused by different particles do not overlap. In this case one can consider the light scattering cross section conditioned by only director distortion near the single particle. Assume that the wave vector $\vec{k}$ of the incident light is directed along the undistorted nematic director which coincides with the $z$-axis of Cartesian frame.

Due to the azimuthal symmetry of the problem, the scattering matrix $\hat{S}$ reduces to the following form:

$$
S_{i j}=(k R)^{2} \int_{1}^{\infty}\left[\delta_{i j} J_{0}(k R \xi \sin \delta)-\frac{1}{2 \pi} \int_{0}^{2 \pi} P_{i j}(\xi, \varphi) \mathrm{e}^{\mathrm{i} k R \xi \sin \delta \cos \varphi} \mathrm{d} \varphi\right] \xi \mathrm{d} \xi,
$$


where we put $r^{\prime \prime}=R \xi, \varphi$ is the azimuth angle of vector $\vec{r}^{\prime \prime}$ in the plane $A, \delta$ is the scattering angle, $J_{0}(x)$ is the Bessel function of the zeroth order and matrix $\hat{P}$ can be written as (see, for example, [6])

$$
\hat{P}\left(r^{\prime \prime}, \varphi\right)=\hat{U}(\varphi)\left(\begin{array}{cc}
\mathrm{e}^{\mathrm{i} \Delta_{\mathrm{e}}\left(r^{\prime \prime}\right)} & 0 \\
0 & \mathrm{e}^{\mathrm{i} \Delta_{\mathrm{o}}\left(r^{\prime \prime}\right)}
\end{array}\right) \hat{U}^{-1}(\varphi) .
$$

Here $\hat{U}(\varphi)$ is a matrix of rotation on the angle $\varphi$

$$
\hat{U}(\varphi)=\left(\begin{array}{cc}
\cos \varphi & \sin \varphi \\
-\sin \varphi & \cos \varphi
\end{array}\right)
$$

$\Delta_{\mathrm{e}}\left(r^{\prime \prime}\right), \Delta_{\mathrm{o}}\left(r^{\prime \prime}\right)$ denote the phase shift, respectively, of the extraordinary and ordinary rays which have passed the director field inhomogeneity relative to the ray passing the undisturbed region. In our case the index of refraction of the last equals the index of refraction of the ordinary ray, so

$$
\Delta_{\mathrm{o}}\left(r^{\prime \prime}\right)=0, \quad \Delta_{\mathrm{e}}\left(r^{\prime \prime}\right)=2 k \int_{0}^{\infty}\left\{\left[\cos ^{2} \psi+\left(\frac{n_{\mathrm{o}}}{n_{\mathrm{e}}} \sin \psi\right)^{2}\right]^{-1 / 2}-1\right\} \mathrm{d} z
$$

where $\psi=\psi\left(r^{\prime \prime}, z\right)$ is the director deviation angle from the undisturbed state, $n_{\mathrm{o}}, n_{\mathrm{e}}$ are the two principal indices of refraction of LC. Expression for the function $\psi\left(r^{\prime \prime}, z\right)$ was obtained for the case of weak director anchoring on the spherical particle surface in paper [3] and for the case of infinitely rigid director anchoring in paper [7].

After substitution of expressions (3)-(6) into formula (1) one can get the following expression for differential cross section

$$
\begin{aligned}
& \frac{\mathrm{d} \sigma}{\mathrm{d} \Omega}=\sigma_{0} \frac{(k R)^{2}}{4 \pi}\left[\left(C_{+}^{2}+D_{+}^{2}\right) \cos ^{2} \alpha+\left(C_{-}^{2}+D_{-}^{2}\right) \sin ^{2} \alpha\right], \\
& C_{ \pm}=\int_{1}^{\infty} B_{\mp}\left(\cos \Delta_{\mathrm{e}}-1\right) \xi \mathrm{d} \xi, \quad D_{ \pm}=\int_{1}^{\infty} B_{\mp} \sin \Delta_{\mathrm{e}} \xi \mathrm{d} \xi \\
& B_{ \pm}=J_{0}(k R \xi \sin \delta) \pm J_{2}(k R \xi \sin \delta), \quad \sigma_{0}=\pi R^{2} .
\end{aligned}
$$
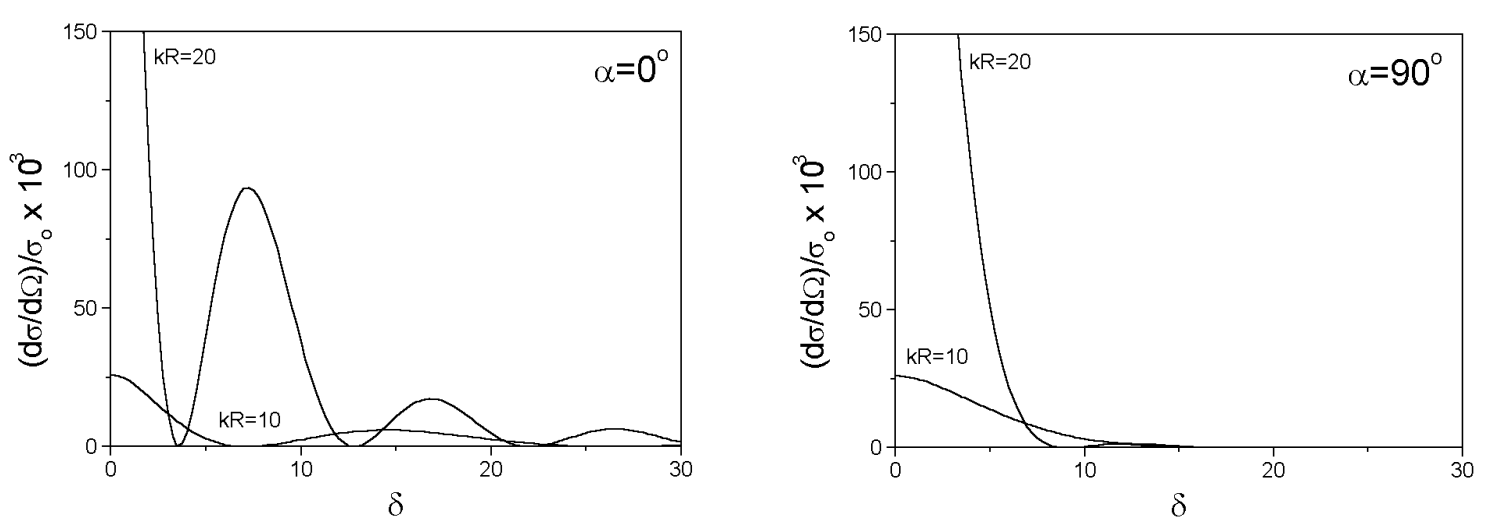

Figure 1. The angular dependence of the differential cross section in the case of spherical particles for two polarization angles of the incident light $\left(\alpha=0^{\circ}, 90^{\circ}\right)$ and $k R=10,20$. 
The $\mathrm{d} \sigma / \mathrm{d} \Omega$ as a function of scattering angle $\delta$ for two cases of the incident light polarization and two values of $k R$ is presented in figure 1 . Here director anchoring on the particle surface is assumed homeotropic and infinitely rigid.

At the weak director anchoring $(W R / K \ll 1$, where $W$ is the director anchoring energy, $K$ is the Frank elastic constant) the angular dependence of $\mathrm{d} \sigma / \mathrm{d} \Omega$ is approximately the same as shown in figure 1 but is smaller by six orders of value.

As is shown in our calculations, the total light scattering cross section increases monotonically with the increase of $k R$ for both $\alpha=0^{\circ}$ and $\alpha=90^{\circ}$.

\section{LC filled with cylindrical particles}

Let the wave vector of the incident light be directed as in the previous section. We consider the only case when the long axis of cylindrical particle is parallel to the $x$-axis of the Cartesian frame. Denoting the angle between the $x z$-plane and scattering plane by $\gamma$, one can write the scattering matrix as

$$
\hat{S}=\hat{U}(\gamma) \hat{S}(\gamma=0) \hat{U}^{-1}(\gamma)
$$

where

$$
\hat{S}(\gamma=0)=\frac{(k R)^{2}}{2 \pi} \iint_{(A)}[\hat{1}-\hat{P}(\gamma=0)] \mathrm{e}^{\mathrm{i} k R x \sin \delta} \mathrm{d} x \mathrm{~d} y
$$

Here $\hat{P}(\gamma=0)$ is defined by formula (4) and $x^{\prime \prime}=R x, y^{\prime \prime}=R y ; R$ is a radius of cross section of cylindrical particle.

Substituting the expressions (10), (11) into formula (1) and performing evident transformations one can obtain the following expression for light scattering differential cross section

$$
\frac{\mathrm{d} \sigma}{\mathrm{d} \Omega}=4 \sigma_{0} \frac{(k R)^{2}}{\pi^{3}}\left(\left|S_{1}\right|^{2} \cos ^{2} \alpha_{0}+\left|S_{2}\right|^{2} \sin ^{2} \alpha_{0}\right)
$$
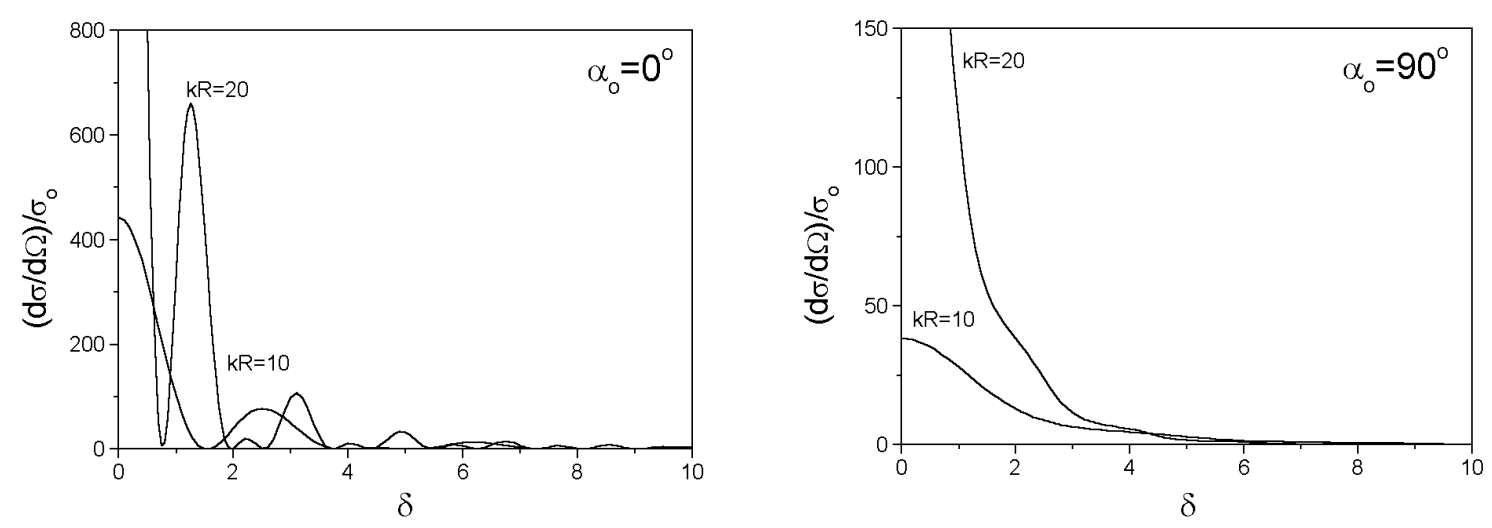

Figure 2. The angular dependence of the differential cross section in the case of cylindrical particles for two polarization angles of the incident light $\left(\alpha=0^{\circ}, 90^{\circ}\right)$ and $k R=10,20$. 
where

$$
\begin{aligned}
S_{1,2} & =S_{1,2}^{\prime}+\mathrm{i} S_{1,2}^{\prime \prime}=\int_{1}^{\infty}\left(1-\mathrm{e}^{\mathrm{i} \Delta_{\mathrm{e}}(y)}\right) F_{1,2}(y) \mathrm{d} y \\
F_{1}(y) & =\int_{0}^{p} \frac{x^{2}}{x^{2}+y^{2}} \cos (k R x \sin \delta) \mathrm{d} x, \\
F_{2}(y) & =\int_{0}^{p} \frac{y^{2}}{x^{2}+y^{2}} \cos (k R x \sin \delta) \mathrm{d} x .
\end{aligned}
$$

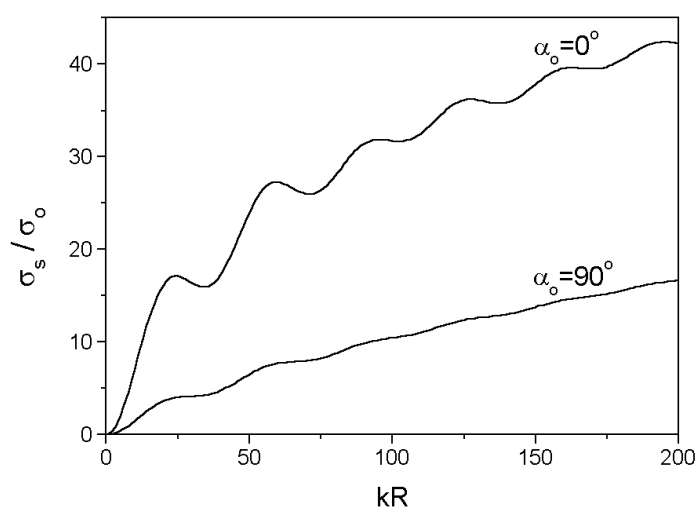

Figure 3. The dependence of the total cross section on $k R$ for different angles of polarization of the incident light $\left(\alpha=0^{\circ}, 90^{\circ}\right)$.

Here $p=L / R, 2 L$ is the length of cylindrical particle, $\alpha_{0}=\alpha+\gamma$. The spatial distribution of the director distortion angle near the cylindrical particle is obtained in papers $[8,9]$. Using these results one can fulfil the numerical calculations of $\mathrm{d} \sigma / \mathrm{d} \Omega$. In figure 2 we present $\mathrm{d} \sigma / \mathrm{d} \Omega$ versus the scattering angle $\delta$ at the infinitely rigid homeotropic anchoring on the cylindrical particle surface for two values of angle $\alpha_{0}$ and $k R=10,20$. At the numerical calculations we put the length of particle $2 L=20 R$.

The analogous dependence takes place in the case of infinitely rigid planar (azimuthal) anchoring on the particle surface too but the value of $\mathrm{d} \sigma / \mathrm{d} \Omega$ is approximately half.

Shown in figure 2, the angular dependence of $\mathrm{d} \sigma / \mathrm{d} \Omega$ conserves its behaviour at the weak director anchoring on the particle surface as well. But the values of $\mathrm{d} \sigma / \mathrm{d} \Omega$ in this case are smaller by six orders similar to the case of the spherical particles.

In figure 3 the total cross section versus $k R$ is shown for two polarization angles of the incident light at the infinitely rigid homeotropic anchoring on the cylindrical particle surface.

\section{Conclusions}

The character of the angular dependence of the light scattering differential cross section in FLCs depends essentially on the polarization of the incident light, on the form and size of particles but does not depend on the type and strength of director anchoring on the particle surface. In other words, the particular character of director spatial distribution near the particle does not practically exert influence on light scattering. It says in favour of the diffraction type of light scattering in the region of validity of the ADA. 
Intensity of light scattering depends essentially on the size of director inhomogeneity area which is conditioned both by the strength of the director anchoring on the particle surface and by the size of the particle.

\section{Acknowledgements}

Work supported by INTAS grant 97-1315.

\section{References}

1. Kreuzer M., Tschudi T., Eidenschink R. Erasable optical storage in bistable liquid crystal cells. // Mol. Cryst. Liq. Cryst., 1992, vol. 223, p. 219-227.

2. Kreuzer M., Eidenschink R. Liquid Crystals in Complex Geometries. ed. G.P.Crawford and S.Žumer. Taylor \& Francis, 1995.

3. Pinkevich I., Reshetnyak V. Influence of small particles on the spatial director distribution and light scattering in nematic cell. // Mol. Cryst. Liq. Cryst., 1998, vol. 321, p. $145-164$.

4. Lednei M., Pinkevich I., Reshetnyak V. Light-scattering by small solid spherical particles dispersed in a nematic cell. // Mol. Cryst. Liq. Cryst., 1999, vol. 331, p. 601-608.

5. van de Hulst H.C. Light Scattering by Small Particles. Wiley, New York, 1957.

6. Zuumer S. Light scattering from nematic droplets: Anomalous-diffraction approach. // Phys. Rev. A, 1988, vol. 37, No. 10, p. 4006-4015.

7. Kuksenok O., Ruhwandl R., Shiyanovskii S., Terentjev E. Director structure around a colloid particle suspended in a nematic liquid crystal. // Phys. Rev. E, 1996, vol. 54, No. 5, p. 5198-5203.

8. Burylov S., Raikher Yu. Orientation of a solid particle embedded in a monodomain nematic liquid crystal. // Phys. Rev. E, 1994, vol. 50, No. 1, p. 358-367.

9. Lednei M., Pinkevich I., Reshetnyak V., Sluckin T. Rayleigh-Gans theory of light scattering in filled nematics. // Mol. Cryst. Liq. Cryst., 1999 (in press). 


\title{
Розсіяння світла на наповнених рідких кристалах у підході аномальної дифракції
}

\author{
М.Ф.Ледней ${ }^{1}$, І.П.Пінкевич ${ }^{1}$, Т.Й.Слуцкін ${ }^{2}$
}

1 Київський національний університет ім. Тараса Шевченка, Фізичний факультет, 03022 Київ, просп. Глушкова, 6

2 Університет Соухемптона, факультет математичних досліджень, Соухемптон, SO17 1BJ, Великобританія

Отримано 1 серпня 2000 p.

Проведено теоретичне вивчення диференційного та повного поперечних перерізів розсіяння світла на рідких кристалах, що містять тверді макроскопічні сферичні та ціліндричні частинки, у підході аномальної дифракції. Проаналізовано вплив форми і розміру частинок, типу і сили закріплення директора на поверхні частинок, а також поляризації світлових хвиль на розсіяння світла.

Ключові слова: рідкі кристали, розсіяння світла, підхід аномальної дифракції

PACS: $61.30 . \mathrm{Cz}, 42.70 . \mathrm{Df}, 61.30 . \mathrm{Gd}, 61.30 . \mathrm{Hn}, 61.30 . P q$ 
